remaining 3 cases we could obtain no information. Of the children who survived, 15 were entirely breast-fed; 32 had been breast-fed for varying periods; 10 had never been breast-fed ; of 6 we could get no history.

Thirteen children developed poliomyelitis under the age of 6 weeks -6 died and 7 survived. Of the 7 survivors, 5 were entirely breast-fed, and, of these, 3 had a mild attack (category $\mathrm{C}$ ).

In the absence of a history of poliomyelitis in the mother. or knowledge of whether she had had an undiagnosed attack, we are unable to make any deductions of value from these figures.

The following are the details of the six cases in which the mother also had poliomyelitis.

Case 1. J.F.T.-The mother died of poliomyelitis six days after the baby was born. This baby died of poliomyelitis at the age of 10 days.

Case 2. R.H.H.-The mother died of poliomyelitis on the fifth day of the puerperium. The child developed poliomyelitis at the age of 10 days and had a very severe attack (category A).

Case 21. A. D.T.-The mother contracted an abortive attack of poliomyelitis at the same time as the child. The child-aged 9 weeks-contracted a serious attack of poliomyelitis (category A).

Case 33. O.H.G.-The mother contracted an abortive attack of poliomyelitis at the same time as the child. The child contracted poliomyelitis at the age of 13 weeks and had a serious attack.

Case 39. S.F.-The mother had a severe attack of poliomyelitis seven days before the child. The child contracted poliomyelitis at the age of 15 weeks and had a mild attack.

Case 51. A. B.-The mother had poliomyelitis two days before the baby. The child developed poliomyelitis at the age of 17 weeks and had a mild attack (category $\mathrm{C}$ ).

History of Immunization or any Operative Procedure

We inquired in every case whether the child had been immunized or subjected to any operation. In view of the fact that all the children were under 6 months it is not surprising to find that only one of them had been immunized, and this was against whooping-cough. The injection was in the right arm, and took place six to eight weeks before admission to hospital. Paralysis was limited to the left leg.

Only one child had been vaccinated against smallpox. Vaccination took place at the age of 4 weeks, and the child contracted poliomyelitis at the age of 22 weeks. This case (R. D. A.) was fatal.

One child (B. O.) had an operation for pyloric stenosis on August 4. On August 14 the mother noticed that the child had difficulty in breathing. He was readmitted to hospital on the 17th and died on the 18th.

\section{Pre-paralytic Symptoms}

In view of the difficulty of diagnosis of poliomyelitis in infants, we have attempted to assess the importance of the pre-paralytic symptoms which have been recorded. Table IV sets out the position.

\section{TABLe IV.-Pre-Paralytic Symptoms}

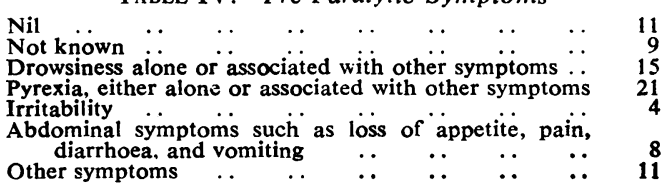

We are of the opinion, judging from the above Table and from the reading of individual case sheets, that in this series there were no definite pre-paralytic symptoms diagnostic of poliomyelitis ; they were rather symptoms of any acute infection in the first six months of life.

\section{Summary}

A report is presented of 82 cases of poliomyelitis in children under 6 months which occurred in England and Wales during 1950 . Of the 82 cases, 77 were paralytic and 5 non-paralytic.
The incidence of paralytic poliomyelitis in infants under 6 months was $56.6 \%$ of what it would have been if such incidence had been equally distributed in sixmonths age groups in children under 15 years.

Non-paralytic poliomyelitis is infrequently diagnosed in children under 6 months.

The overall mortality rate was $23 \%$, and this mortality increased as age diminished. In children under 9 weeks the mortality rate was $37.5 \%$.

Of the 58 paralytic cases who survived, 30 were either very severely or severely paralysed, and of these only 2 made a complete recovery.

We have discussed the influence of breast feeding on the incidence and course of the disease.

The pre-paralytic symptoms were not diagnostic except of an acute infection in a child under 6 months.

REFERENCES

Bousfield, G. (1951). Lancet, 1, 1028.

Geffen $\dot{D}$. Paterson, H. and Tracy, S M (1953) Ibid. 1, 1268

Health Services of Israel, 1952.

Legan W. P D (1952), Monthly Bull. Minist. Hlth, Lond 11, 147.

Logan, W. P. D. (1952). Monthly Bull. Minist. Hith, Lond., 11, 147.

mallpeice, V., and Ounsted. C. (1952). J. Neurol., 15, 13

\section{Medical Memoranda}

\section{Acute Strychnine Poisoning after a Massive Dose}

Deaths from strychnine poisoning are not uncommon and have been exhaustively dealt with in the literature. The interest of the present case lies in $(a)$ the enormous dose which must have been taken and the rapidity with which death occurred; $(b)$ the little evidence of any of the classical symptoms of strychnine poisoning; and $(c)$ the further evidence of the extreme rapidity of absorption of the drug from the alimentary canal.

\section{CASE REPORT}

The deceased was a pharmacist aged 56. At 10 o'clock one morning, having dispatched all but one of his assistants on various errands, he retired to a room over the shop. Eighteen minutes later he was found in this room by an assistant, lying on a couch with his head on the seat and his legs dangling over the raised end. Examination by a doctor five minutes later proved life to be extinct, and it seems probable that he was already dead at 10.18 , when found by the assistant. There is good evidence, therefore, that death ensued at the most 15 minutes after swallowing the poison, and probably rather less. When the body was examined by the doctor there was no trace of any muscular rigidity. It is probable that if there had been any violent convulsions before death the man would not have remained on the couch but would have rolled off on the floor. Beside the body was found a partly filled bottle of solution of strychnine hydrochloride, and crystals of what later proved to be strychnine hydrochloride were found in the deceased's mouth, down the front of his pullover, and on the floor surrounding the body.

The necropsy findings were largely negative apart from rather meagre evidence of asphyxia.

The viscera were subjected to the classical Stas-Otto extraction. The residues from the chloroform-caustic-soda extraction were heated on a water bath for 30 minutes with concentrated sulphuric acid, diluted with water, filtered, made alkaline, and re-extracted with chloroform. Removal of the chloroform yielded a white, crystalline, weighable residue which was proved to be practically pure strychnine by melting-point determination and titration. This last was effected by dissolving the residue in $0.01 \mathrm{~N}$ sulphuric acid and back-titrating with $0.01 \mathrm{~N}$ caustic soda, using methyl orange as an indicator. From the titration figures the fol- 
lowing amounts of strychnine hydrochloride were calculated to be in each organ : liver, $125 \mathrm{mg}$.; kidneys, $30 \mathrm{mg}$; bowel, 4,608 mg. ; stomach and contents, $653 \mathrm{mg}$. ; blood, $4 \mathrm{mg}$. per $100 \mathrm{ml}$.; urine, trace.

If we assume a circulation volume of 5 litres the total amount of strychnine in this would be $200 \mathrm{mg}$. There is, therefore, a total recovery of about $5.6 \mathrm{~g}$. (84 gr.) of strychnine from the main viscera. It was estimated that the deceased had consumed $12 \mathrm{fl}$. oz. $(340 \mathrm{ml}$.) of solution of strychnine hydrochloride (containing about 53 gr. $(3.4 \mathrm{~g}$.) of strychnine hydrochloride), but the amount of crystalline strychnine hydrochloride taken was not known.

J. T. A. Lloyd, M.C., M.B., D.P. Department of Pathology, Royal Alexandra Hospital, Rhyl.

E. Pedley, M.Sc., F.R.I.C., Ph.C.

North-western Forensic Science Laboratory, Preston.

\section{Primary Carcinoma Simulating Empyema of the Gall-bladder}

Primary carcinoma of the gall-bladder is the fifth or sixth in order of frequency of cancers of the alimentary system. It is found in from 1 to $2.6 \%$ of all gall-bladder operations, in $0.42 \%$ of all necropsies, and in $2.8 \%$ of all cases of malignant disease. These figures are given by Illingworth (1935), who studied 50 cases. Judd and Gray (1932), Lichtenstein and Tannenbaum (1940), Kirshbaum and Kozoll (1941), Vadheim, Gray, and Dockerty (1944), Benjamin (1948), and Sainburg and Garlock (1948), and other American surgeons have all reported numerous examples. The following two cases, however, seem remarkable enough to warrant publication.

\section{CASE 1}

A compositor aged 78 was admitted on July $5,1949 . \mathrm{He}$ had been well until a fortnight before, when he noticed a dull aching pain between the shoulder-blades. This persisted for a week, when he visited his doctor, who found he was jaundiced. He then admitted that his urine had been dark in colour for about 10 days. On examination the liver was palpable two fingerbreadths below the costal margin and the gall-bladder was felt below it.

On July 14 the serum bilirubin was $22.4 \mathrm{mg}$. per $100 \mathrm{ml}$. blood cholesterol, $380 \mathrm{mg}$. per $100 \mathrm{ml}$. ; blood urea, $25 \mathrm{mg}$. per $100 \mathrm{ml}$; thymol turbidity, 1 unit; colloidal gold, 0 ; alkaline phosphatase, 64 units; serum protein, $6.4 \%$ (albumin $2.9 \%$, globulin $3.5 \%$ ). On July 29 the abdomen was opened through a right paramedian incision. Several pints of ascitic fluid escaped. The liver was cirrhotic and the gall-bladder large and tense with a sugar-icing surface. The gall-bladder was opened and cheese-like material removed with a spoon. It was excised with difficulty and a T-tube was placed in the common bile-duct. The patient became drowsy after the operation, gradually weakened, and died on July 31,26 days after admission. Biliary cirrhosis, thrombosis of the hepatic vessels with patchy necrosis, and some metastases in the liver were found at necropsy.

Pathology.-The gall-bladder was $9 \mathrm{~cm}$. long and $5.5 \mathrm{~cm}$. in diameter. It was completely filled with yellow cheese-like material. Microscopically, no normal mucosa was seen. The wall was infiltrated by an ill-differentiated adenocarcinoma, which was forming acini in some places and not in others. The nuclei were large and vesicular with prominent nucleoli. There was very little mucin production. The material in the lumen had the structure of necrotic tumour and contained some pyknotic nuclei.

\section{CASE 2}

A secretary aged 52 first attended as an out-patient on December 11, 1950, complaining of bouts of pain between the shoulder-blades and on the right side of the abdomen, with occasional pain on the left side. She had always had to be careful what food she ate, but had never been jaundiced. On examination she was seen to be of sallow complexion. A swelling was felt below the ribs on the right side, and on January 3,1951, a cholecystogram showed no filling of the gall-bladder. On February 5 the abdomen was opened by a right paramedian incision and a greatly enlarged gall-bladder presented. It was slightly inflamed, and the many adhesions were divided. Because of the size of the gall-bladder, a retrograde cholecystectomy was performed and the abdomen was closed with a drain. On February 20 the patient was discharged from hospital, having made an uneventful recovery. She was seen last on September 5 of that year, when she complained of occasional attacks of pain, but on examination nothing abnormal was found.

Pathology.-The gall-bladder weighed $460 \mathrm{~g}$. and was $17.5 \mathrm{~cm}$. long and $7 \mathrm{~cm}$. in diameter. The surface in contact with the liver was 8.5 by $6 \mathrm{~cm}$. Large veins coursed over its surface. It was filled with grey cheese-like material, which when washed away from the wall left a shaggy lining. There were 20 mixed faceted calculi; the largest, $1.5 \mathrm{~cm}$. in diameter, was impacted in Hartmann's pouch. There was a thickening up to $0.5 \mathrm{~cm}$. of the wall of the organ on the ventral surface $5 \mathrm{~cm}$. from the fundus. Microscopically, the contents of the gall-bladder could be demonstrated as masses of necrotic cancer. A section of the thickened wall showed a columnar-cell papillary adenocarcinoma growing in long trabeculae in a fine stroma. The cells were producing a little mucus and had large dark-staining nuclei with frequent mitoses. The wall of the gall-bladder did not appear to be completely penetrated by tumour at any point, and a section of the cystic duct showed no neoplastic tissue.

\section{Discussion}

In both these cases, following a short history of symptoms referable to the biliary tract, a laparotomy was performed, and a grossly enlarged gall-bladder filled with cheese-like material was removed. In neither case was a diagnosis made until microscopical examination revealed an adenocarcinoma growing into the lumen of the organ. The cheese-like material was necrotic cancer, and there was no evidence of infection. Illingworth (1935) observed that the papillary type of carcinoma might reach a considerable size, partly filling the gall-bladder. It was prone to haemorrhage and necrosis, and might be so soft as to be mistaken for inspissated pus. In the series of 48 cases examined by Cooper (1937) $12 \%$ had papillary tumours, and some of these distended the gall-bladder. Rhodes and Greenblatt (1937) describe obstruction of the cystic duct by tumour as a cause of distension of the gall-bladder, which may simulate an empyema, but they make no mention of the organ being filled with necrotic tumour. Vadheim, Gray, and Dockerty (1944) found that 26 of their 77 cases had gall-bladders distended to four times the normal size, but the largest carcinoma they encountered measured only 7 by 6 by $5 \mathrm{~cm}$. It is interesting to note that in 17 of their cases the carcinoma was limited to the mucosa and submucosa without penetration of the muscularis.

It therefore appears that the two tumours described are very large examples of a type recorded by some authors, but by no means universally recognized. A grave error would be made if cholecystostomy were performed in such a case.

My thanks are due to Mr. Ralph Shackman and Mr. Rodney Smith for permission to publish the cases and to Professor T. Crawford for his assistance in preparing the paper.

\section{A. J. M. REeSE, M.D.,} Department of Pathology. St. George's Hospital Medical School, London.

REFERENCES

Benjamin, E. G. (1948). Minn. Med., 31, 537 Cooper, W. A. (1937). Arch. Surg., Chicago, 35, 431 Illingworth, C. F. W. (1935). Brtt. J. Surg. 23, 4 . Judd, E. S., and Gray, H. K. (1932). Surg. Gynec. Obstet., 55, 308 Kirshbaum, J. D., and Kozoll, D. D. (1941). Ibid., 73, 740. Lichtenstein, G. M.. and Tannenbaum, W. (1940). Ann. Surg., 111, 411 Sainburg. F. P., and Garlock, J. H (1948), Surgery 23 201 . Vadheim, J. L., Gray, H. K., and Dockerty, M. B. (1944). Amer. J. 